\title{
ARQUEOLOGÍA DE LA DESAPARICIÓN
}

\section{The Archaeology of Disappearance}

\author{
Alfredo González Ruibal* \\ Incipit-CSIC
}

\begin{abstract}
Palabras clave
Arqueología del pasado contemporáneo Subjetividad Violencia política Campos de concentración Basura de seres humanos y la aniquilación de subjetividades como parte de un sistema de eliminación más amplio, en el cual se incluye la ocultación del ciclo de consumo capitalista. A partir de ejemplos concretos, argumento que el poder contemporáneo se oculta o virtualiza para llevar a cabo la desaparición; que existe una homología entre la aniquilación de personas y cosas (con la basura como concepto unificador), que la desaparición de la desaparición (el borrado de huellas) es imposible y que la arqueología permite frustrar la fantasía de los perpetradores. El artículo concluye con la descripción de dos casos de estudio que representan la transformación de las economías de desaparición a lo largo de casi un siglo: un campo de concentración como paradigma de la vieja economía y un espacio de marginalidad como ejemplo de la nueva.
\end{abstract}

\section{Keywords}

Archaeology of the Contemporary

Past

Subjectivity Political Violence Concentration Camps Rubbish

RESUMEN: En este texto analizo la economía de la desaparición de los siglos $x x$ y xxI desde un punto de vista arqueológico. Abordo, desde postulados biopolíticos, la desaparición física

ABSTRACT: I explore here the economy of disappearance of the Twentieth and Twenty-first Centuries from an archaeological point of view. Starting from biopolitical premises, I examine the physical disappearance of human beings and the annihilation of subjectivities as part of a larger system of elimination, in which the concealment of the capitalist cycle of consumption is included. Based on specific examples, I argue that contemporary power hides or is virtualized in order to carry out the work of disappearance; that there is a homology between the annihilation of people and things (with the concept of waste underpinning both); that the work of making disappearance disappear (the erasure of traces) is impossible and that archaeology can thus thwart the fantasy of the perpetrators. The article concludes with two case studies which represent the transformation of the economies of disappearance throughout almost one century: a concentration camp as paradigm of the old economy and a space of marginality as an example of the new one.

\footnotetext{
* Correspondencia a / Correspondence to: Alfredo González Ruibal. Incipit-CSIC. Avenida de Vigo, s/n (15705 Santiago de Compostela) - alfredo.gonzalezruibal@incipit.csic.es - http://orcid.org/0000-0003-3464-1626.

Cómo citar / How to cite: González Ruibal, Alfredo (2020). Arqueología de la desaparición. Papeles del CEIC, vol. 2020/1, papel 225, 1-20. (http://dx.doi. org/10.1387/pceic.20764).
}

Recibido: abril, 2019; aceptado: octubre, 2019.

ISSN 1695-6494 / (C) 2020 UPV/EHU 


\section{INTRODUCCIÓN1}

Mi intención con este texto es doble: reflexionar sobre la economía de la desaparición en el marco de la hipermodernidad y explorar las posibilidades de la arqueología a la hora de revelar el funcionamiento de dicha economía. Como arqueólogo me interesan particularmente tres cuestiones: en primer lugar, la tecnología de la desaparición, entendida al mismo tiempo desde un punto de vista foucaultiano y estrictamente material; la segunda, referida al contexto material de la desaparición y la tercera, centrada en el aspecto material que adopta la desaparición de la desaparición. En relación con la primera cuestión, me interesa cómo se hace desaparecer a la gente en la práctica y cuáles son los pasos que se siguen, los objetos y espacios que se emplean en cada uno de los pasos y, quizá lo más característico desde un punto de vista arqueológico, cuáles son las trazas, los desechos, los restos que dejan cada una de las etapas del proceso técnico. Parafraseando a Foucault (1997: 26), se podría decir que se trata no tanto de aprehender «la instancia material de subyugación en tanto que constitución de sujetos», sino la "la instancia material de aniquilación en tanto que disolución de sujetos». De la misma manera que aparecen «nuevas técnicas a través de las cuales el individuo puede integrarse en la entidad social» (Foucault, 2000: 410), aparecen también nuevas técnicas para desintegrar individuos (campos de exterminio, ciencias antropobiológicas racistas, bombas nucleares). Porque durante el siglo $x \mathrm{x}$ el poder no se ha dedicado exclusivamente a constituir sujetos, sino también a deconstituirlos, expulsándolos del cuerpo social o desintegrándolos por completo: las sombras de cuerpos humanos dejadas por la explosión de la bomba atómica en Hiroshima son la manifestación más clara de esta tanatopolítica (Foucault, 2000: 416; Mbembe, 2003), el negativo de la biopolítica. Como ésta, también "ha tomado cuerpo en las técnicas y se ha dotado de instrumentos de intervención material» (Foucault, 1997: 25). Sin embargo, no se trata de una arqueología foucaultiana, sino de una literal: del estudio de la materialidad de las cadenas técnicas operativas de la desaparición (González-Ruibal, 2016a; Lemonnier, 1992).

En segundo lugar, me preocupa el contexto material más amplio de la desaparición. Parto de la idea de que desaparecer no es algo relacionado exclusivamente con el exterminio de oponentes políticos, aunque esta sea su manifestación más extrema. La aniquilación absoluta (que conlleva la destrucción física, el borrado de las huellas de dicha destrucción y la eliminación de la memoria de lo aniquilado) es un fenómeno recurrente en una variedad de regímenes de los últimos cien años. Entiendo que la desaparición de oponentes políticos no representa una opción más entre las muchas que se encuentran a disposición de las dictaduras o una solución a problemas coyunturales o una manifestación particular de sadismo, aunque sea todo eso también. La desaparición ("dejar de existir») y el aniquilamiento ("reducir a la nada») deben entenderse que constituyen, juntos, un pilar insustituible de la metapolítica hipermoderna.

\footnotetext{
Quiero agradecer a todos los compañeros del seminario sobre desapariciones que tuvo lugar en Bilbao en enero de 2019 por sus comentarios y críticas constructivas, que han ayudado enormemente a mejorar este texto. También por los maravillosos trabajos que presentaron, que me han servido para reflexionar sobre nuevos conceptos y formas de acercarse al problema de la desaparición. Agradezco asimismo a dos evaluadores anónimos la atenta lectura de este texto y sus sugerencias y correcciones. Los errores que pudieran persistir son de mi autoría.
} 
Por metapolítica me refiero a una cosmovisión política (una cosmopolítica) que va más allá de ideologías concretas y regímenes de poder: por ejemplo, la política de la naturaleza del socialismo real y de las democracias capitalistas fueron prácticamente indistinguibles durante el siglo xx. Aniquilación y desaparición no son equivalentes. La desaparición no implica necesariamente la aniquilación, y de hecho aquí analizaré contextos donde priman una $u$ otra, según las circunstancias políticas y las metas que se persiguen. Es una premisa central en mi argumento que la hipermodernidad supone un período excepcional y bien delimitado en la historia humana. Parto del concepto de sobremodernidad (surmodernité) de Marc Augé (1992), que entiende dicho fenómeno como una versión excesiva de la modernidad que se plasma en la espacialidad, la temporalidad y el yo. Teniendo en cuenta, además de los fenómenos mencionados por Augé, la dimensión material y la política -en concreto la necropolítica (Mbembe, 2003) - creo que se puede hablar de hipermodernidad desde la transición del siglo xIx al xx y sin ninguna duda a partir de la Primera Guerra Mundial. Por lo que respecta al fenómeno de la desaparición, es precisamente en esas fechas cuando emergen dos fenómenos característicos: la guerra total y el genocidio planificado. En tercer lugar, me interesa el aspecto material que adopta la desaparición de la desaparición y particularmente la forma en que la arqueología puede intervenir para desvelar dicho proceso: el desmantelamiento de campos de exterminio, la destrucción de fosas comunes y el borrado de huellas de las instalaciones destinadas a la fabricación o prueba de artefactos nucleares (Theune, 2018).

Partiendo de las premisas mencionadas, en los siguientes apartados describiré, en primer lugar, las formas en que el poder desaparece en la hipermodernidad (ocultación, dispersión y virtualización); a continuación abordaré las formas de continuidad entre la desaparición material y humana y lo que ello revela de la racionalidad hipermoderna y examinaré el fenómeno de la desaparición de la desaparición, es decir, la eliminación de las trazas de aniquilamiento. El último apartado aborda dos casos de estudio en el que se comparan sendas formas de desaparición (vieja y nueva) a través de sus huellas arqueológicas.

\section{DESAPARICIÓN Y PODER: OCULTACIÓN, DISPERSIÓN, VIRTUALIZACIÓN}

La hipermodernidad ha convertido en una tarea ordinaria lo que hasta entonces había sido extraordinario: la desaparición absoluta. Puede ser el aniquilamiento de grupos humanos completos, la devastación del medio ambiente -la deforestación del Chaco para el monocultivo de la soja (Gordillo, 2014) - o la destrucción exhaustiva de paisajes construidos. Esta última no ocurre necesariamente en el marco de un conflicto armado: el aniquilamiento de Shanghai bajo los efectos del capitalismo avanzado es superior al que haya provocado ninguna guerra en una megalópolis (Ren, 2014). La desaparición, por lo tanto, se convierte en una más entre las muchas técnicas a disposición de la gubernamentalidad a la hora de establecer "la correcta disposición de las cosas» (Foucault, 2000: 208). En algunos casos, se considera que la única forma de lograr dicha disposición es mediante su total aniquilación. La desaparición tiene una dimensión transitiva e intransitiva en relación al poder hipermoderno: el poder hace desaparecer y el poder mismo desaparece. Por un lado, elimina todo aquello que incomoda o no encaja en una determinada idea de disposición correcta de las cosas o que obstaculiza la eliminación. Por otro lado, el poder mismo se vuelve menos físico. "Todo poder será tenebroso o no será, pues toda potencia visible está amenazada», escribe Virilio 
(1988: 24) siguiendo a Balzac². Podemos incluso concluir que hacer desaparecer solo es posible desapareciendo uno mismo, de la misma manera que cazar solo es posible mimetizándose uno en el paisaje, volviéndose invisible. En el caso de los crímenes de lesa humanidad el recurso a la invisibilidad lo motiva una cuestión de eficacia tanto práctica como política.

La desaparición implica simultáneamente tres fenómenos: ocultación, virtualización y dispersión. La ocultación es una de las obsesiones de la hipermodernidad y funciona a todos los niveles. El proceso de ocultación se puede trazar desde los orígenes mismos de la modernidad. Durante el siglo xvi la generalización de la artillería lleva a la creación de fortificaciones más bajas y menos conspicuas en el paisaje. Para el siglo XVIII la gran mayoría de los fuertes no sobresale apenas del entorno. Al llegar el xx, la potencia de fuego de que disponen los ejércitos conduce a la construcción de fortificaciones bajo el suelo y por lo tanto muy difíciles de localizar y destruir. Los estados mayores y gobiernos que dirigieron la Segunda Guerra Mundial en Europa ( $y$ sus exterminios correspondientes) lo hicieron en buena medida bajo tierra. Al mismo tiempo, a los uniformes de colores típicos de los ejércitos de los siglos XVIII y XIX los sustituyen otros que permiten al soldado mimetizarse con el paisaje (Virilio, 1988: 104). Las técnicas del ocultamiento no han cesado de crecer y volverse más complejas: desde los submarinos a los aviones indetectables al radar.

El poder hipermoderno no desaparece solo en el momento de ejecutar el golpe. También trata de no ser visto a posteriori. Una doble ocultación que resulta también única de nuestra era: los asirios o los romanos se preocupaban mucho de que sus masacres y destrucciones fueran bien visibles. Incluso las inmortalizaban en piedra. Todo lo contrario de lo que sucede en la actualidad. Eyal Weizman (2017: 69-71) habla del «umbral de detectabilidad», en el cual las cosas se mueven entre la posibilidad de ser y no ser identificadas. Es el caso de las chimeneas de los hornos crematorios o las columnas de presos de Auschwitz, que se encuentran en el límite de lo técnicamente discernible en las fotografías aéreas tomadas por los Aliados durante la guerra. Con la tecnología de que disponemos actualmente, el umbral de detectabilidad podría ser irrelevante, dada la altísima precisión de las imágenes satelitales. Sin embargo, las que se hacen públicas tienen una resolución limitada a 0,5 metros por pixel por motivos político-militares, lo cual oculta detalles clave en cualquier investigación forense (Weizman, 2017: 74-75), lo que quiere decir que amplios espacios del planeta se convierten en zonas desaparecidas, impenetrables al escrutinio público: «el pixel», escribe Weizman, "se ha convertido en una especie de zona ex-territorial» (2017: 79). La manipulación del pixel es el equivalente virtual a la destrucción física de fosas comunes o campos de exterminio: se trata de eliminar las pruebas incriminatorias, eliminar la eliminación. Es significativo que esta proliferación de desapariciones-virtualizaciones desplegadas por el poder comience en el arranque de lo que Paul Virilio (2005: 13) ha denominado la «Era de la llusión», es decir, un período -que coincide con la hipermodernidad como se define aquí- en el cual la política está mediatizada por tecnologías de engaño masivo: desde el cine hasta los medios de comunicación $y$ los efectos especiales.

No obstante, la ocultación tiene raíces más profundas. La forma de poder que emerge en la transición de los siglos XVII y XVIII y que sustituye al poder soberano previo es un régimen disciplinario en el cual las coacciones se encuentran "ocultas como ejercicio efectivo de po-

2 El autor de este artículo ha sido incapaz de encontrar la cita original de Balzac. Es posible que Virilio la haya parafraseado muy libremente. 
der» (Foucault, 1997: 33). Al espectáculo barroco de la soberanía sustituye un ejercicio del poder mucho menos visible, que se materializa en espacios, instrumentos y saberes. Frente a la ley que sustenta el poder soberano, nos encontramos ahora con la regla natural, es decir la norma, que se basa no en la jurisprudencia sino en las ciencias (Foucault, 1997: 34). Los peligros de este nuevo régimen de poder son evidentes: por un lado, crea una "sociedad de la normalización» (Foucault, 2000: 328), en la que resulta mucho más complejo deconstruir el discurso del poder; por otro, la racionalización del poder político lleva fácilmente a los excesos mientras la armazón del poder permanece en la oscuridad. Es indudable que las aniquilaciones invisibles del siglo $x x$ resultaron posibles y exitosas porque se fundamentaban en esta forma de poder. El poder soberano del Antiguo Régimen habria sido incapaz de llevar a cabo con éxito el exterminio de grupos enteros, tanto por cuestiones prácticas (el orden en las ejecuciones en masa de judíos se mantenía gracias al engaño respecto al destino final que esperaba a las víctimas) como éticas: al desplazar, ocultar e higienizar la masacre se evitan los problemas que causa el rechazo instintivo de la violencia espontánea y física de los pogromos (Bauman, 2000: 99-100).

Por lo que respecta a la dispersión, este es uno de los temas foucaultianos por antonomasia, la microfísica del poder. Cuando hablamos de tecnologías de la desaparición, los conceptos foucaltianos (micromecánica, capilaridad del poder, operadores materiales, utilización de sistemas locales) toman un aspecto mucho más concreto y físico. La desaparición a gran escala requiere de una materialización institucional amplia y compleja, una infraestructura al mismo tiempo física y administrativa. En la imaginación colectiva, el genocidio perpetrado por los nazis se efectuó en media docena de centros de exterminio. Sin embargo, el funcionamiento de estos campos sería imposible sin una tupida red de campos y subcampos dispersos a lo largo de Europa, de infraestructuras relacionadas (guetos, vías de tren, carreteras, fosas comunes, cuarteles, edificios administrativos) (Sturdy Colls, 2015: 199-233) y de multitud de individuos (desde los Gauleiter al guardarraíles, el campesino ucraniano y el hapo). El caso del Holocausto es extremo por su alcance espacial, su efectividad y el número de víctimas. Pero en realidad todos los sistemas de desaparición contemporáneos se basan en un sistema de capilaridad semejante. Así, en el caso de la Guerra civil española, la reutilización de edificios como checas, cárceles improvisadas o campos de concentración hizo desaparecer la diferencia entre espacio cotidiano y espacio de represión, la distinción entre el dentro y el afuera (Colombo, 2011), una indeterminación que, como en el caso de la Unión Soviética, facilitó la imposición de una atmósfera de terror paralizante y al mismo tiempo el propio proceso de desaparición de las víctimas (González-Ruibal, 2016a). Lo mismo sucedió en el caso de las dictaduras latinoamericanas (Salerno et al., 2012; Santos Herceg, 2016).

Finalmente, la virtualización se encuentra estrechamente ligada a los dos fenómenos ya descritos. El término lo utiliza Olivier Razac (2015) para referirse al hecho de que el poder hipermoderno necesita realizar una menor inversión material para lograr sus objetivos. Siguiendo su argumentación, las murallas de piedra son sustituidas por el alambre de espino, que es sustituido por la supervisión electrónica. Cada paso implica un aligeramiento material sin que se pierda eficacia técnica, más bien al contrario: la virtualización implica una mayor efectividad en el control. El mayor control imaginable (chips implantados bajo la piel que permiten geolocalizar a una persona allá donde vaya) es el más efectivo y al mismo tiempo el más invisible. El poder logra aqui plenamente la fantasía de la desaparición. La virtualización, en cuanto desmaterialización, posee además otro significado y otra funcionalidad. Los espacios concentracionarios se distinguen de espacios de represión tradicionales (como la 
cárcel o el patíbulo) en su aniquilación del espacio-tiempo, la cual se alcanza, entre otras cosas, mediante la desinversión material en los lugares de represión. Este es un elemento común a los campos nazis (Sofsky, 2013), los campos de concentración franquistas en España (González-Ruibal, 2016a) y los centros de detención de la última dictadura argentina (Colombo, 2011). Una prisión es, en muchos sentidos, el polo opuesto a un campo de concentración, en la medida en que se trata de un espacio hiperregulado e hiperconstruido: existen celdas, corredores, comedores, talleres y patios y la ocupación de cada espacio tiene un tiempo perfectamente pautado en la vida del recluso. Los campos de concentración, en cambio, se caracterizan por un número mínimo de marcadores materiales: puede ser un simple espacio delimitado por alambre de espino sin más (caso de muchos campos franquistas), puede ser un cubículo mínimo (como en los centros de detención argentinos). Según Colombo, la forma en que se secuestra, recluye, asesina y desaparece el cadáver tienden a producir una experiencia que se desarrolla en "ningún lugar» (Colombo, 2011: 642) ¿Qué forma más radical de virtualización/ desmaterialización que la aniquilación misma del lugar?

\section{DESAPARICIÓN MATERIAL, DESAPARICIÓN HUMANA}

"La evolución de la cultura semeja la marcha de un ejército constituido en su mayoría por rezagados. Quizá yo viva en 1913, pero un vecino mío vive en 1900 , y otro, en $1880 . .$. Los paisanos de los altos valles del Tirol viven en el siglo xII... Feliz el país libre de rezagados y merodeadores», escribe Adolf Loos (apud Virilio 1988: 105), padre del racionalismo arquitectónico. Su deseo de una arquitectura pura sin adorno alguno, estrictamente funcional y homogénea no es más que la aspiración moderna a un espacio social asimismo homogéneo y limpio. En un régimen liberal, la desaparición se realiza mediante una mezcla de control, represión y educación -de "policia» (Foucault, 2000: 318-319)—, es decir, mediante la biopolítica. En un régimen totalitario la limpieza toma la forma de la aniquilación, es decir, de tanatopolítica. Pero permanece el elemento higiénico: de ahí que hablemos de "limpieza étnica», para referirnos al genocidio, o de "operaciones de limpieza en la retaguardia», para el exterminio de partisanos o disidentes políticos.

Que la desaparición es algo que va más allá de la desposesión y eliminación de los enemigos políticos y sus cuerpos se demuestra de forma particularmente clara en aquellos casos en los cuales el asesinato en masa del contrario ha ido de la mano de procesos de destrucción sistemática del paisaje. En la Unión Soviética, durante los años de las purgas estalinistas (19361938) se hizo desaparecer a cientos de miles de personas al tiempo que se aniquilaba física y simbólicamente la capital de la Unión Soviética y el paisaje pre-revolucionario en general: «la antigua aldea con su iglesia en la plaza más visible, con sus mejores casas en un primer plano, las del guardia, el pope, el kulak, con sus cabañas de campesinos semiderruidas en el fondo: todo eso empieza a desaparecer», escribe Stalin (apud Schlögel, 2014: 353). Forma parte todo de la misma tecnología de desubjetivación: no basta con exterminar a las personas, es necesario también aniquilar la presencia material del antiguo orden. El mismo doble exterminio, humano y material, tuvo lugar en los territorios devastados por el genocidio nazi: mientras se asesinaba a los judíos, se incendiaban sinagogas y las lápidas de los cementerios se convertían en material constructivo (Bartov, 2007). 
Lo que debe desaparecer se suele asociar con el desecho. Gabriel Gatti (2008) habla de la materialidad de las identidades propias e impropias en la modernidad. Las identidades propias son sólidas, homogéneas y limpias - como a las que aspira el estalinismo, el nazismo o el fundamentalismo-. Según Gatti, su modelo de materialización es el patrimonio, pero podríamos hablar también de los monumentos y la arquitectura. En cambio, las identidades impropias, sucias, fragmentarias - la de los marginados y expulsados del sistema dominante- tienen como correlato material la basura, con la cual, además, se identifican en el relato hegemónico. La basura es esencial para entender las políticas de la desaparición. Se ha señalado muchas veces que el eliminacionismo se fundamenta en una deshumanización del Otro (Bauman, 2000; Haslam, 2006; Kelman, 1973). Dicha deshumanización se suele entender como animalización (y con frecuencia se encuentran comparaciones con ganado, alimañas, perros, ratas, gusanos, etc.), pero quizá sería más apropiado hablar de una cosificación. Haslam (2006), de hecho, distingue formas de deshumanización animalistas y mecanicistas.

La cosificación, sin embargo, consiste en algo más que en la transformación del Otro en cosa inanimada, porque a las cosas no se las trata como a las víctimas de la violencia genocida. El eliminacionismo transforma al Otro en desecho, que es el grado más bajo de existencia: es equivalente a materia inanimada (por lo tanto inferior a cualquier ser vivo por simple que sea biológicamente); pero además, materia amorfa - no objeto, sino cosa pura, inútil-y además nociva, degradación de la cosa. La basura es «el contrario necesario de la identidad», el lugar de "monstruos varios» (Gatti, 2008: 5). Es también una materia abyecta, que atenta contra nuestros sentidos. Tratamos de librarnos de ella cuanto antes, la desplazamos fuera de nuestra vista, la incineramos o la enterramos para que no quede rastro. La basura nos produce disgusto porque es una afrenta sensorial, pero también porque en última instancia nos reconocemos en ella, sabemos que es parte de nosotros, de la misma manera que los nazis se reconocían en sus prisioneros y ese reconocimiento incrementaba su odio y su violencia. Nos encontramos en nuestros detritos y nos avergonzamos de ellos porque la basura, como indicó Elías Canetti (2010: 325), es también la prueba de todos nuestros crímenes. En el caso de los desechos domésticos puede tratarse de una dieta insana, de un consumismo irresponsable y excesivo (Rathje y Murphy, 1992). En el caso de los desechos humanos producidos por el eliminacionismo, es la mácula de una acción necesaria pero excesiva, que ha trasgredido todos los límites morales - de ahí que el arrepentimiento y la vergüenza sean tan comunes entre los perpetradores tras el final de un ciclo eliminacionista (Goldhagen, 2010)-. En ambos casos, desearíamos que desaparecieran sin dejar rastro alguno, para sentirnos libres de culpa, como si nunca hubieran existido. Esto, sin embargo, no es un hecho generalizado: en el caso del Cono Sur, los testimonios de arrepentimiento son más escasos que en otros contextos y la desaparición obedece en exclusiva a razones funcionales.

"La suciedad es materia fuera de lugar... Donde hay suciedad, hay un sistema» -escribió Mary Douglas (2004: 44) - Da lo mismo que la suciedad sea material o humana. Lo que está fuera de lugar pueden ser desechos orgánicos, objetos rotos e inservibles, personas, sociedades, ecosistemas; es significativo que en la mentalidad moderna la selva se haya asociado habitualmente al desorden (la «jungla»). En cualquiera de estos casos, la hipermodernidad autoritaria ha recurrido a la desaparición, que no es incompatible con el reciclaje: la uinternalización de la basura» (Gatti, 2008: 10). El cabello, la grasa y las cenizas de los exterminados en las cámaras de gas se reutilizaron de múltiples maneras. Las cenizas, por ejemplo, como fertilizante o para asfaltar carreteras (Dziuban, 2017: 266). Los bosques tropicales se convierten 
en madera o serrín. La suciedad es una ofensa contra el orden: «eliminarla no es un acto negativo, sino un esfuerzo positivo para organizar el medio" (Douglas, 2004: 2). Lo cual nos devuelve nuevamente a Foucault y su concepto de gubernamentalidad como la forma de disponer correctamente las cosas. La desaparición, por lo tanto, responde en última instancia al cumplimiento de una fantasía de orden, el precio que hay que pagar para lograr una identidad homogénea y limpia. No solo se trata de perseguir fines simbólicos, sino económicos: la desaparición de judios y eslavos en el oriente de Europa era el paso previo a la colonización del territorio por parte de productivos alemanes, mientras que la aniquilación de la selva es menos un objetivo en sí mismo que el deseo de transformar un espacio percibido como improductivo en productivo.

\section{DESAPARICIÓN DE LA DESAPARICIÓN}

Si el aniquilamiento absoluto es uno de los signos de la hipermodernidad, otro lo es, como he señalado, el empeño en hacer desaparecer sus trazas. Nunca en la historia pusieron los gobernantes tanto esfuerzo en limpiar las huellas de sus crímenes. Pero lo cierto es que nunca en la historia hubo una divergencia tan grande entre ética, tecnología y política. La era del genocidio y la desaparición es también el período en el que nos parece moralmente más reprobable el asesinato de personas indefensas, cuando se generaliza el Habeas Corpus, cuando surge el derecho internacional humanitario, la justicia universal y los derechos humanos. La economía de la desaparición solo puede existir en la sombra.

Los nazis volaron los cuatro campos polacos creados con el fin exclusivo del exterminio durante la segunda mitad de 1943, se aró la tierra, se plantaron pinos y se construyeron granjas para eliminar cualquier rastro de su existencia (Gilead et al., 2010). En Chile, se quemaron y demolieron los centros de detención tras su uso, en plena dictadura (Santos Herceg, 2016). El mismo proceso de borrado de huellas sucede en el caso de conflictos incómodos. El escritor Jonathan Littell visitó Chechenia como miembro de una ONG durante las dos guerras que arrasaron la región entre 1999 y 2005. Tres años después del final del conflicto regresó a Grozni, la capital, que había sido reconstruida por las autoridades rusas. Apenas pudo reconocer la ciudad: "Se podría decir sin exagerar que París parece conservar más trazas de la Segunda Guerra Mundial en las paredes de caliza de sus ministerios y museos, que Grozni de sus dos guerras» (Littell, 2014: 258). El objetivo de la reconstrucción rápida y sistemática es principalmente permitir que la gente pueda habitar la ciudad y contentar una región castigada por la violencia ejercida por el mismo país que ahora reconstruye. Pero también es indudable que permite borrar el pasado, hacerlo desaparecer como si nunca hubiera existido. Lo dice un SS ${ }^{3}$ en la primera página de Los hundidos y los salvados de Primo Levi:

«De cualquier manera que termine esta guerra, la guerra contra vosotros la hemos ganado nosotros; ninguno de vosotros quedará para dar testimonio de ella, pero incluso si alguno lograra escapar el mundo no lo creería. Quizá haya sospechas, discusiones, investigaciones de los historiadores, pero no podrá haber ninguna certeza, porque con vosotros serán destruidas las pruebas.» (Levi, 1986: 3).

3 Miembro del Schutzstaffel (SS), organización encargada del control de los campos nazis. 
Refiriéndose al desmantelamiento de los centros chilenos, Santos Herceg (2016: 260) escribe: «El tipo de destrucción al que se recurre es generalmente, total y definitiva». De forma similar se expresa Olivier Razac (2015: 72): "Un muro deja rastro, una cerca de alambre de espino, no». Sin duda este pensamiento explica en parte el uso sistemático de estructuras efímeras fabricadas con alambre, chapa y madera en los campos de concentración y exterminio desde el régimen nazi a las dictaduras actuales. No se trata solo de ahorrar costes y agilizar la construcción y desmontaje, sino también de facilitar la eliminación de las huellas de los crímenes. La fantasía de la desaparición absoluta tiene fe en los materiales que la posibilitan. Pero es una fe infundada.

Si en algo puede contribuir la arqueología es a poner en evidencia las estrategias de desaparición de la desaparición que desarrollan los regímenes políticos dictatoriales. La mera destrucción de las pruebas es un elemento incriminador. Las investigaciones arqueológicas en campos de exterminio nazi llevan años documentando tanto las trazas de lo que sucedió en ellos como los intentos de ocultarlo. El uso de técnicas de excavación convencionales y nuevos métodos de prospección geofísica están permitiendo identificar huellas hasta ahora invisibles (Gilead et al., 2010; Kola, 2000; Pawlicka-Nowak, 2004; Sturdy Colls, 2015; Theune, 2010).

Naturalmente, las estructuras que los nazis pusieron más empeño en eliminar eran precisamente aquellas que servían para hacer desaparecer a la gente: las cámaras de gas y los crematorios. En el caso de Mauthausen, los nazis sellaron el orificio de la pared de la habitación donde se situaba el aparato que dispensaba el gas. Sin embargo, el examen geofísico de la pared y el análisis tipológico detallado de las baldosas permitió identificarlo y reconstruir la secuencia de construcción, uso y sellado. La prospección geofísica, a su vez, ofreció una imagen precisa del orificio por donde se dispensaba la sustancia tóxica (Theune, 2018). En Sachsenhausen, al excavar el camino empedrado que llevaba a la cámara de gas, aparecieron prótesis dentales y otros objetos pequeños incrustados entre las piedras (Theune, 2018). También se descubrieron elementos relacionados con las víctimas judías en Chelmno, en los sótanos y el pasillo por el cual debían marchar los prisioneros desnudos camino del camión de gas (Pawlicka-Nowak, 2004).

Poseemos ejemplos arqueológicos de centros de internamiento desmantelados exhaustivamente en otros contextos. En Argentina, a la demolición del Club Atlético siguió la construcción de una carretera sobre los restos, lo cual no pudo impedir que las excavaciones arqueológicas descubrieran los sótanos del edificio. Allí aparecieron un montacargas, tres celdas de aislamiento, la enfermería y los baños y quirófanos (Salerno et al., 2012). En otro centro, la Mansión Seré, los militares provocaron una explosión e incendiaron el edificio para borrar pruebas de su uso, pero nuevamente la arqueología puso al descubierto la estructura del edificio, que muestra su distribución interna, y numerosos objetos relacionados con el período de uso represivo (Salerno et al., 2012). En España, el campo de concentración de Castuera (Badajoz) estuvo en funcionamiento entre abril de 1939 y abril de 1940, inmediatamente después de la guerra civil española (González-Ruibal, 2016b). Los trabajos arqueológicos sacaron a la luz numerosas pruebas del desmantelamiento del recinto (chapas, clavos, fibrocemento, arandelas de zinc) y de la alambrada de espino (el alambre mismo y piquetas para sujetarlo). Además descubrimos que el barracón de los guardias había sido reutilizado por parte de los últimos presos encargados de desmontar el campo: sobre el suelo encontramos elementos constructivos, así como latas y hogueras que señalan los sitios donde los presos descansaban 
y comian, entre ellos, la letrina. Las estancias fueron demolidas y rellenadas de escombro tras el abandono final del recinto.

Si bien la demolición de un centro de internamiento puede dificultar la interpretación de los restos, difícilmente puede ocultar su naturaleza. La presencia de decenas o cientos de miles de seres humanos en muchos de ellos ha dejado un enorme volumen de artefactos enterrados. Se calcula que en el campo de tránsito de Westerbork (Holanda) puede haber hasta 5.2 millones de objetos (Schute, 2018: 604). En Buchenwald, en una zona de solo 32 metros cuadrados se efectuaron 6.500 hallazgos, entre ellos 4.000 botones (Theune, 2018: 79). Además de ofrecer testimonio material sobre la cantidad de gente víctima del exterminio, los objetos son un signo también del proceso de desubjetivación - de disolución del sujeto- en el cual intervienen los vagones de ganado, el alambre de espino, la desposesión de objetos personales, la desnudez, el asesinato en masa, la cremación y el descarte de las cenizas. Es significativo que de toda la masa de artefactos documentada en campos nazis solo un pequeño porcentaje corresponda a objetos personales (Starzman, 2014) y son menos aun los que se pueden relacionar con individuos particulares (Schute, 2018: 604). Los objetos son parte fundamental en nuestra constitución como personas. Hacerlos desaparecer es el primer paso en la aniquilación del sujeto. En el caso de los campos de exterminio es muy difícil recuperar la identidad individual de las víctimas, pero sí que es posible, a partir de los objetos perdidos, recobrar identidades colectivas. Se ha otorgado un énfasis especial a la recuperación de individuos, lo cual encaja bien con las formas modernas de subjetividad, pero en el caso de los asesinatos políticos no debería ser menos importante identificar sujetos colectivos: judíos, mujeres, comunistas, jornaleros o niños. Al fin y al cabo, muchas veces fue la solidaridad de grupo la que los condujo a la fosa común o al campo de exterminio.

La imagen más potente de la aniquilación total es el humo que salía de los crematorios en los campos de exterminio nazis. Sin embargo, incluso la cremación deja rastro en forma de cenizas. Como he señalado, los nazis (y los polacos) reutilizaron las cenizas en la construcción y como fertilizante. Sin embargo, se siguen documentando grandes cantidades de ceniza en los campos de concentración y exterminio, normalmente asociadas a pequeños fragmentos de huesos humanos (Sturdy Colls, 2015). En las excavaciones de Sachsenhausen se localizó recientemente un contenedor de cenizas asociado a un crematorio (Theune, 2018). Cuando el contenedor se llenaba, las cenizas se transferian a unas grandes fosas excavadas en las cercanías del horno. En otros campos de exterminio, como Chelmno, Sobibor y Belzec se ha verificado la presencia en fosas comunes de enormes cantidades de ceniza, fragmentos de hueso (Pawlicka-Nowak, 2004), e incluso cabellos y grasa humana (Kola, 2000). Las cenizas, escribe Dziuban, son testimonio de la «destrucción completa e irrevocable de lo que ya no es, pero también la realidad de algo que persiste, están ahí, como la única cosa que ha sobrevivido a la incineración» (2017: 285).

En crímenes más recientes existen otras formas de borrar huellas: en el caso de la ex-Yugoslavia se ha documentado el vaciado de fosas y el traslado de restos. Los estudios osteológicos y los análisis de ADN han permitido conectar huesos de los mismos individuos dispersos en varias fosas (Skinner et al., 2002). En Uruguay, la «Operación Zanahoria» llevada a cabo por los militares entre 1983 y 1985 tenía como objetivo eliminar pruebas de la existencia de fosas comunes con represaliados políticos. Si bien muchas desaparecieron, las intervenciones arqueológicas lograron identificar anomalías estratigráficas, elementos óseos humanos aislados y huellas de maquinaria (López Mazz, 2017), lo cual confirma al mismo tiempo la existencia de fosas y la operación por hacerlas desaparecer: dos crímenes en lugar de uno. En 
España, la intervención en las fosas de Mérida (Badajoz) puso al descubierto una doble aniquilación: por un lado, solo se documentaron fragmentos pequeños de huesos, botones, hebillas y otros objetos menores, que demuestran que las fosas se vaciaron en algún momento de la posguerra. Por otro lado, se encontraron trazas de quemado, reveladoras de la incineración de los cuerpos durante la guerra (Muñoz Encinar, 2016: 157-158).

\section{VIEJAS Y NUEVAS DESAPARICIONES: DOS EJEMPLOS}

Dos casos que he podido investigar personalmente ilustran con claridad algunos de los temas que he tratado a lo largo del artículo $y$, particularmente, el vínculo entre desaparición, desecho y grupos eliminables. Se trata de dos espacios muy distintos y que responden a lógicas políticas igualmente distintas. En el primer caso se trata de un campo de concentración, es decir del paradigma biopolítico del siglo xx según Agamben (1995). El segundo caso, un espacio intersticial de hipermarginación urbana, constituye un ejemplo característico de las formas de desaparición del siglo XXI. Ambos tienen en común la forma en que hacen desaparecer sujetos y los transforman en desecho social.

Los campos de concentración franquista fueron espacios de desaparición (de ellos salían sacas de prisioneros a ser asesinados), de clasificación -en ellos se decidía quien viviría, quien moriría o quien seguiría preso-, de abyección: en los campos se humillaba sistemáticamente a los presos y se los equiparaba al desecho y a las heces hasta el punto que dicha identidad (o más bien, no-identidad) era, sino asimilada al menos interiorizada, de forma que la mayor parte de quienes pasaron por los campos no volvieron a hablar de la experiencia y llevaron consigo la marca de la vergüenza hasta la muerte (Hernández de Miguel, 2019). La relación entre los detritos fisiológicos, el desecho social y los republicanos estaba muy presente en la mentalidad franquista. Isidro Castrillón López, alcaide de la Cárcel Modelo de Barcelona, se dirigió a los presos en 1941 diciéndoles: "tenéis que saber que un preso es la diezmillonésima parte de una mierda» (Rodrigo, 2008: 165). El espectáculo de los prisioneros en los campos era ciertamente desolador: el médico republicano Bastos Ansart (1969: 354) habla de "Grandes rebaños de rojos, sucios, harapientos, miserables, con el espanto pintado en sus facciones demudadas, que eran llevados a encierros entre soldados nacionales arma al brazo». En la propaganda franquista, esta situación de degradación física no tenía que ver tanto con las penosas condiciones del cautiverio como con la propia esencia del "ser rojo». Así, un periodista afín al régimen se refiere en 1938 a una hilera de presos como "una longaniza de agitada carne maloliente... sucios, desharrapados, los cabellos al aire y en ellos, y en el rostro, desaseado, indicios patentes de un vivir sin orden ni cuidado alguno" (apud Hernández de Miguel, 2019: 192).

El campo de concentración de Castuera, al que me he referido más arriba, ilustra perfectamente el vínculo entre abyección, desaparición y deconstitución de sujetos políticos durante el primer franquismo. Por este campo pasaron cerca de 30.000 personas, cientos fueron asesinadas clandestinamente y un número indeterminado falleció víctima de las condiciones de vida (hambre, enfermedad y maltrato). Durante nuestra investigación en Castuera (GonzálezRuibal, 2016b: 268-286) documentamos dos fosas relacionadas con el centro de detención en las que se recuperaron los cuerpos de 33 individuos (ver Figura 1). Otras fosas (y parte de una de las que exhumamos) fueron destruidas por la ampliación del cementerio. Además de la 
exhumación, también prospectamos y excavamos el campo de internamiento, en concreto las letrinas, que fueron empleadas como basurero. Lo que nos permitió relacionar las fosas con el campo de concentración fue, de hecho, la aparición de materiales semejantes en fosas y letrinas: alambre (que se utilizó en la construcción del campo y para maniatar a las personas que iban a ser asesinadas), monedas en distintos estadios de modificación y anillos de cobre realizados con dichas monedas (que los presos fabricaban para intercambiar por comida), fragmentos de chapa de zinc (del tipo utilizado en los barracones), abrelatas y cucharas.

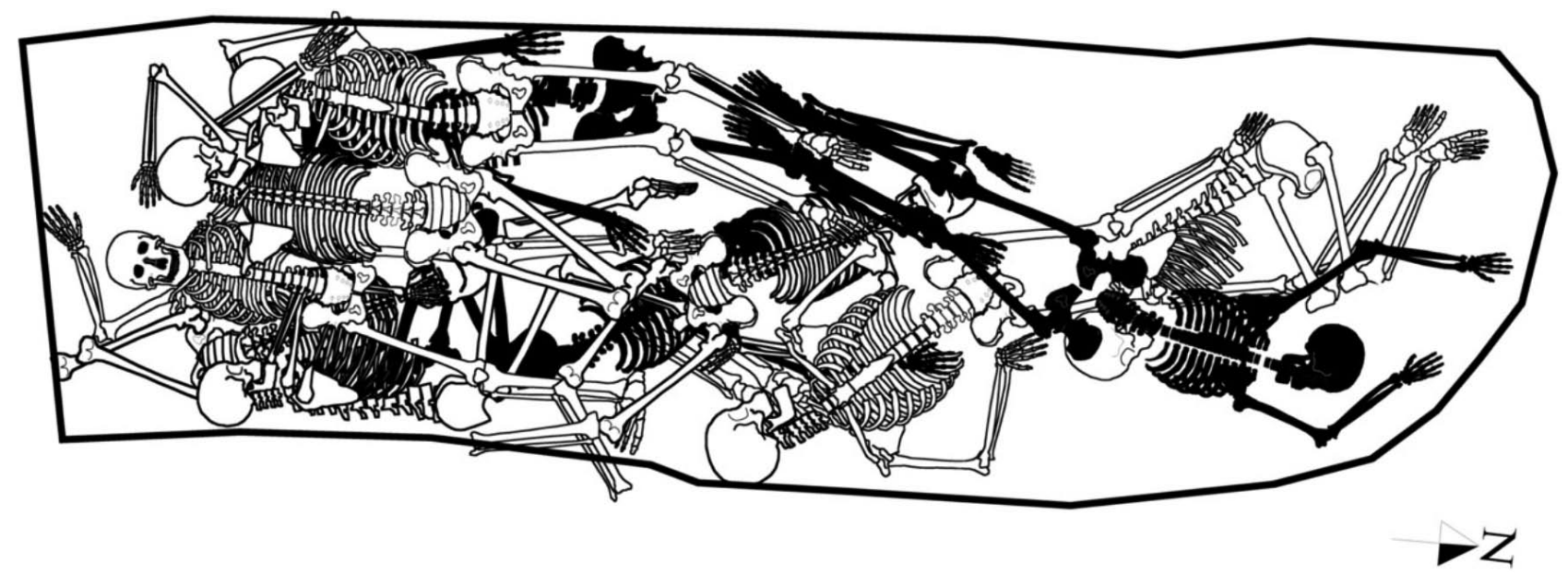

Figura 1

Una de las fosas comunes de Castuera (Badajoz), con 11 individuos. La disposición de los restos indica cómo fueron arrojados a la fosa

Existe una similitud sorprendente entre las letrinas y las fosas. Es una similitud al mismo tiempo formal y estructural. En ambos casos se trata de largas zanjas estrechas y poco profundas que fueron realizadas por los propios prisioneros. La función en ambos casos era hacer desaparecer desechos: desechos fisiológicos, desechos materiales, personas-desecho. En las letrinas los prisioneros republicanos realizaban sus necesidades. Una vez que estaban llenas de heces y orina, se colmataban con basura y tierra y se excavaba otro tramo de letrina (ver Figura 2). En las fosas comunes iban a parar los cuerpos de los asesinados y las pertenencias que llevaban consigo. Cuando se llenaban las fosas, se sellaban con tierra y se abrian otras zanjas. Las letrinas eran un espacio de castigo: los presos debian hacer sus necesidades colectivamente y ante los guardias. Muchos sufrian enfermedades gastrointestinales por la mala y escasa comida, lo que incrementaba la tortura física y moral - todo ello magistralmente descrito por el periodista Eduardo de Guzmán (2001), que sufrió cautiverio-. Las fosas comunes eran un espacio de castigo: el castigo supremo, la aniquilación física. Pero las letrinas también hacian desaparecer: mediante la humillación diaria, eliminaban al sujeto político, con frecuencia de por vida. De ahí que la oposición al régimen fuera prácticamente inexistente entre quienes pasaron por los campos de concentración. Los asesinados desaparecieron físicamente, pero los castigados lo hicieron social y políticamente. Para los verdugos, los guardias de los campos de concentración y los milicianos derechistas es imposible que pasara desapercibida la analogía entre letrina y fosa, aunque fuera inconscientemente. Aprendieron a ver al vencido como basura, tal y como la propaganda del régimen lo describía. 


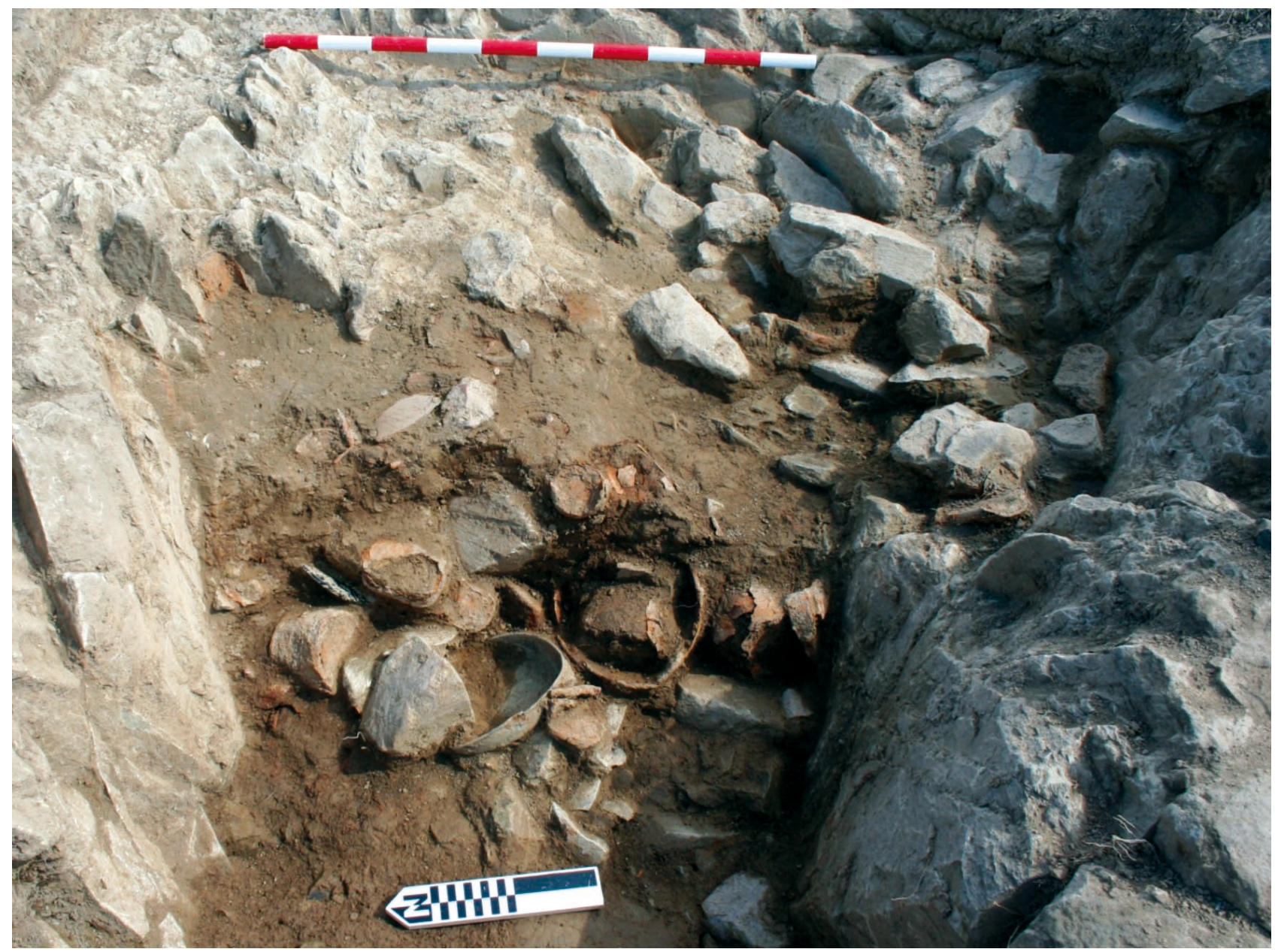

Figura 2

Letrina del campo de concentración de Castuera, convertida en basurero

El otro espacio al que me voy a referir es muy distinto. Se trata de la Ciudad Universitaria de Madrid. Aquí realizamos excavaciones para documentar los restos de la Guerra Civil existentes en el campus, que fue campo de batalla desde noviembre de 1936 hasta marzo de 1939. Durante los trabajos arqueológicos descubrimos mucho más que restos bélicos. De hecho, quizá los hallazgos más interesantes tengan que ver con el periodo de posguerra, desde 1939 a la actualidad. La Ciudad Universitaria de Madrid forma parte de un espacio estrechamente asociado al poder en la capital de España. En la zona en que trabajamos se encuentran, además de los edificios universitarios, el Palacio de la Moncloa, residencia del presidente del gobierno, el Tribunal Constitucional, varios cuarteles del ejército y museos nacionales. Es quizá una de las zonas del país donde se concentra, de forma más evidente, el poder ejecutivo, judicial, militar y epistémico, y lo hace de forma monumental. Sin embargo, en este mismo espacio existen regiones intersticiales semiocultas que constituyen una inversión del espacio hegemónico. En las excavaciones de trincheras y refugios de la Guerra Civil encontramos restos de ocupaciones de gente sin hogar desde 1939 hasta la actualidad (ver Figura 3). 


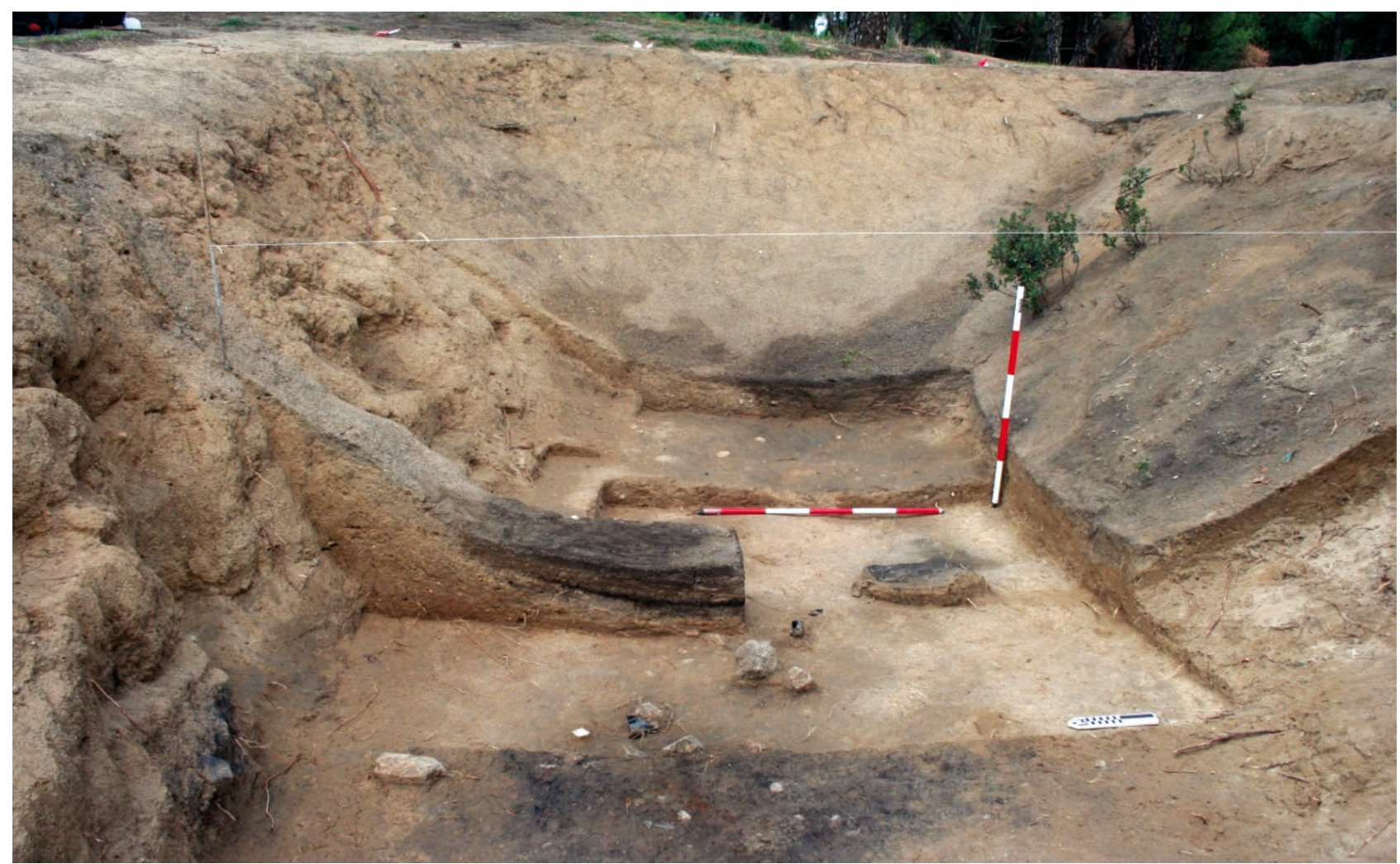

Figura 3

Excavación de un refugio de tropa republicano de la Guerra Civil en la Ciudad Universitaria de Madrid, reutilizado por gente sin hogar en los años 40 y 50

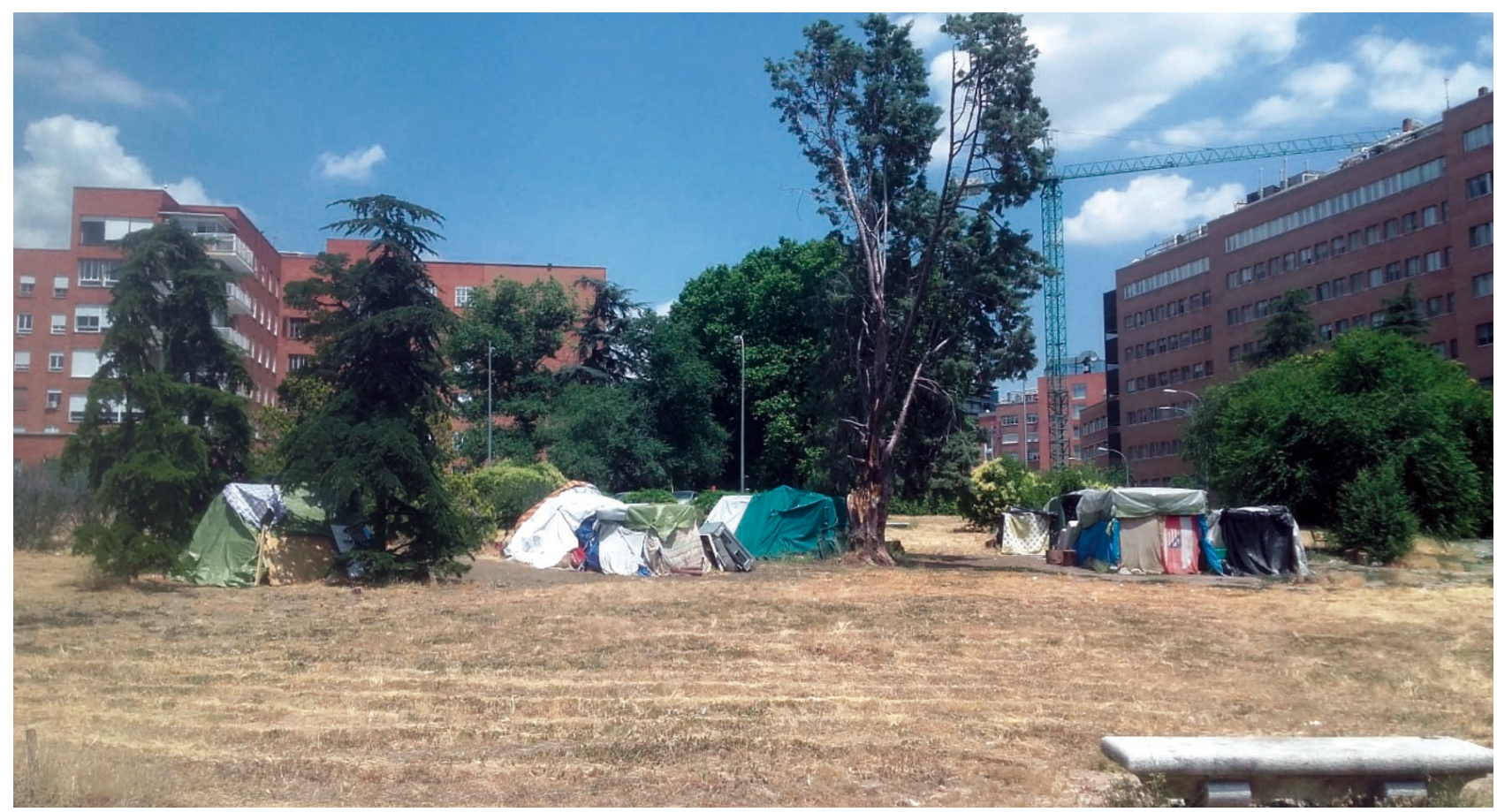

Figura 4

Campamento de romá del este de Europa en un espacio intersticial del campus 
De hecho, todavía hoy, una importante población de marginados habita o frecuenta la zona, incluidos gente sin hogar, drogadictos, inmigrantes subsaharianos sin papeles, una comunidad romá del este de Europa y homosexuales que utilizan una parte del campus ("La Finca de Papá») como zona de encuentro desde hace décadas, quizá siglos (ver Figura 4). Las trazas de todos estos colectivos aparecen como desecho que colmata las estructuras de la Guerra Civil (ver Figura 5). En una sociedad en la cual lo abyecto se encuentra cada vez más apartado y recluido (tanatorios, hospitales, centros de internamiento de inmigrantes, plantas de reciclaje, basureros), las regiones intersticiales rebosan de basura y de gente-desecho. Aquí el detrito no está clasificado y contenido como en los espacios mencionados, pero resulta igualmente invisible. Es como el polvo barrido bajo la alfombra. En última instancia, tanto en el espacio marginal como en el campo de concentración, prevalece un régimen de excepción en el cual se invierte la regla (Agamben, 1995). Quizá no sea casual que tanto el espacio represivo por antonomasia como las regiones intersticiales adopten la misma forma de habitar: el campamento, un espacio desregulado, efímero y a la intemperie.

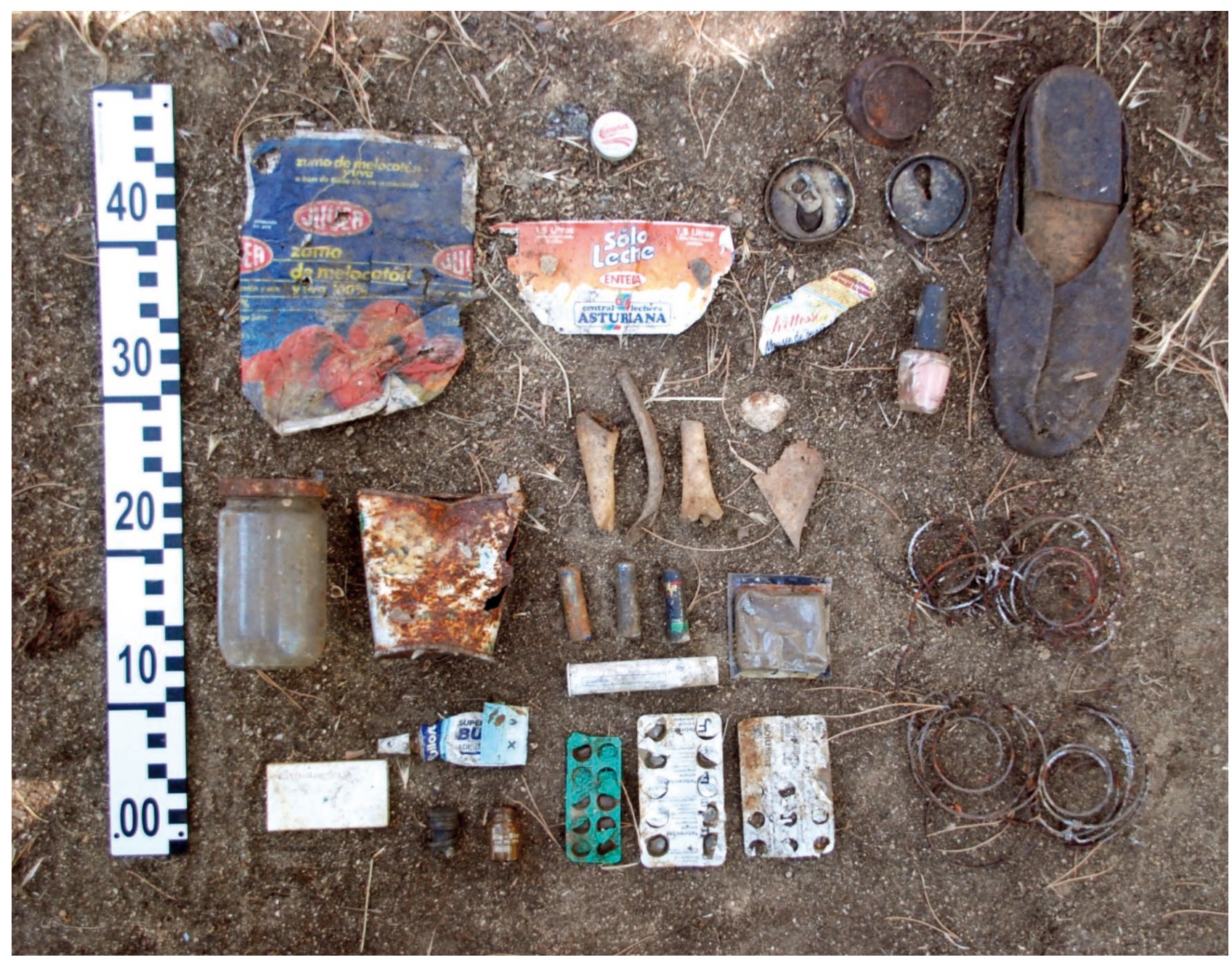

Figura 5

Restos asociados a la ocupación de un abrigo de la Guerra Civil en la Ciudad Universitaria de Madrid por parte de una persona sin hogar, posiblemente una mujer, hacia 1992 
Existe, no obstante, una diferencia importante entre campo y campus. El campo de concentración se desarrolló como una tecnología eficiente para hacer desaparecer sujetos previamente constituidos como tales. Las regiones intersticiales, en cambio, engullen a quienes, en su gran mayoría, nunca han sido considerados sujetos legítimos. Desde un punto de vista jurídico, este es el caso precisamente de los inmigrantes sin papeles (Schindel, 2019). El campus recoge a un aluvión de gente expulsada de la sociedad por los mecanismos de marginación estructurales del capitalismo global. No los hace desaparecer, porque nunca han aparecido en la historia, pero es un lugar de desaparición igualmente, porque impide que los veamos. Según Isin y Rygiel, los espacios abyectos («aquellos en los que y a través de los cuales gentes desplazadas, desposeidas, quedan condenadas al estatus de extranjeros, forasteros y extraños" (2007: 181) hacen desaparecer a quienes los habitan, porque los constituyen no como "sujetos ni objetos, sino algo inexistente, en tanto en que resultan inaudibles e invisibles" (Isin y Rygiel, 2007: 182-183). Por ello no son tratados como sujetos (de disciplina) ni objetos (de eliminación), sino como aquellos "sin presencia, sin existencia» (ibídem: 184).

Los presos asesinados y desaparecidos del campo de Castuera son inaudibles e invisibles, pero también lo son, a todos los efectos, los habitantes de las regiones marginales de la Ciudad Universitaria de Madrid, o los emigrantes fallecidos en el mar, que desaparecen sin sufrir una operación de exterminio (Schindel, 2019). Quizá ese sea el mayor éxito del orden neoliberal: la capacidad de hacer desaparecer sin el problema moral y práctico que implica el asesinato planificado. En los últimos años se ha dedicado mucha atención a los espacios de desaparición que se encuentran en los límites de los estados-nación (fronteras, espacios extraterritoriales). Sin embargo, la desaparición se produce cada vez más en el interior de los estados-nación -lo que Isin y Rygiel (2007: 192) denominan «zonas»-y no solo en espacios geográfica y jurídicamente discretos (Gatti, Irazuzta y Martínez, 2019).

\section{CONCLUSIÓN}

La economía de la desaparición es uno de los rasgos de la hipermodernidad. Se puede decir que el aniquilamiento de seres humanos de otra etnia, la disposición de la basura en grandes vertederos o la desaparición de la selva para el monocultivo no tienen nada que ver entre sí. Sin embargo, en todos los casos responden, en última instancia, a una misma racionalidad. Se trata de un deseo de orden, de conseguir una identidad limpia y homogénea en un espacio igualmente limpio y homogéneo. Pero no llega con limpiar, también es necesario olvidar que hemos limpiado para que no solo el espacio y el tiempo queden inmaculados, sino también nuestra conciencia. De ahí que incluso algo tan inofensivo como la eliminación de desechos no esté exenta de connotaciones políticas. La desaparición diaria de la basura de nuestras casas permite que sigamos consumiendo de forma insostenible. Que los vertederos más contaminantes estén situados cada vez más lejos, que desaparezcan de nuestra vista y se desplacen a África o el sudeste asiático es también parte de una economía de la desaparición.

En este artículo me he acercado al fenómeno de las desapariciones contemporáneas desde una perspectiva arqueológica. La arqueología tiene importantes limitaciones a la hora de generar conocimiento, pero también ofrece alguna ventaja, particularmente cuando se trata de investigar aquello que está oculto, conscientemente o inconscientemente: si los regímenes 
hipermodernos funcionan dentro de una economía de la desaparición, la arqueología lo hace dentro de una epistemología de la aparición, pues su objetivo, en última instancia, es descubrir cosas: sacarlas a la luz, desenterrarlas literalmente: los cuerpos de los asesinados en un campo de concentración, los desechos de la gente sin hogar. Este proceso, además, se realiza en público (Moshenska, 2009), lo que nuevamente combate la tendencia al ocultamiento que es característica de las políticas de la desaparición. Por otro lado, resulta posible arqueológicamente documentar no solo las estrategias de desaparición, sino también la forma en que se hace desaparecer la desaparición, es decir, cómo se borran las huellas de las tecnologías de exterminio. Finalmente, lo abyecto es parte de la materia con la que trabaja la disciplina (Shanks et al., 2004), se trate de basura o restos humanos. En este artículo he enfatizado la importancia de la abyección (la basura, las heces) para comprender los procesos de desaparición en la hipermodernidad, en los cuales se equiparan ideológicamente detritos y personas y se les otorga un tratamiento semejante.

\section{REFERENCIAS}

Augé, M. (1992). Non-lieux. Introduction à une anthropologie de la surmodernité. París: Le Seuil.

Agamben, G. (1995). Homo sacer. Il potere sovrano e la nuda vita. Turín: Einaudi.

Bartov, O. (2007). Erased: Vanishing Traces of Jewish Galicia in Present-Day Ukraine. Princeton, NJ: Princeton University Press.

Bastos Ansart, M. (1969). De las guerras coloniales a la Guerra Civil. Barcelona: Ariel.

Bauman, Z. (2000). Modernidad y holocausto. Barcelona: Sequitur.

Canetti, E. (2010). Masa y poder. Barcelona: DeBolsillo.

Colombo, P. (2011). Espacio y desaparición: los campos de concentración en Argentina. Isegoría, 45, 639-652.

De Guzmán, E. (2001). El año de la victoria. Madrid: VOSA.

Douglas, M. (2004). Purity and Danger: An Analysis of Concepts of Pollution and Taboo. Londres: Routledge.

Dziuban, Z. (2017). Between Subjectification and Objectification. Theorizing Ashes. En Z. Dziuban (Ed.). Mapping the Forensic Turn (pp. 261-288). Viena: New Academic Press.

Foucault, M. (1997). «ll faut défendre la société». Cours au Collège de France. 1976. París: Seuil.

Foucault, M. (2000). Power. En P. Rabinow (Ed.). Nueva York: New Press.

Gatti, G. (2008). Identidades (de la) basura. En E. Imaz (Ed.). La materialidad de la identidad (pp. 41-61). San Sebastián: Hariadna.

Gatti, G., Irazuzta, I., y Martínez, M. (2019). Espacios de excepción invertida. Casas de Migrantes y Santuarios en el tránsito de los migrantes indocumentados hacia Estados Unidos. Ponencia presentada al seminario «Nuevas desapariciones, nuevos espacios». Universidad del País Vasco, Bilbao. 
Gilead, I., Haimi, Y., y Mazurek, W. (2010). Excavating Nazi Extermination Centres. Present Pasts, 1(1), https://www.presentpasts.info/1/volume/1/issue/1/

Goldhagen, D. J. (2010). Peor que la guerra: genocidio, eliminacionismo y la continua agresión contra la humanidad. Madrid: Taurus.

González-Ruibal, A. (2016a). Beyond the Mass Grave: Producing and Remembering Landscapes of Violence in Francoist Spain. En O. Ferrán y L. Hilbink (Eds.). Legacies of Violence in Contemporary Spain (pp. 111-136). Londres: Routledge.

González-Ruibal, A. (2016b). Volver a las trincheras. Una arqueología de la Guerra Civil española. Madrid: Alianza.

Gordillo, G. (2014). Rubble. The Afterlife of Ruins. Durham, NC: Duke University Press.

Haslam, N. (2006). Dehumanization: An Integrative Review. Personality and Social Psychology Review, 10(3), 252-264.

Hernández de Miguel, C. (2019). Los campos de concentración de Franco. Sometimiento, torturas y muerte tras las alambradas. Barcelona: Penguin Random House.

Isin, E. F., y Rygiel, K. (2007). Abject Spaces: Frontiers, Zones, Camps. En C. Masters y E. Dauphinee (Eds.). The Logics of Biopower and the War on Terror (pp. 181-203). New York: Palgrave Macmillan.

Kelman, H. G. (1973). Violence Without Moral Restraint: Reflections on the Dehumanization of Victims and Victimizers. Journal of Social Issues, 29(4), 25-61.

Kola, A. (2000). Bełżec: the Nazi camp for Jews in the light of Archaeological Sources: Excavations 1997-1999. Varsovia: The Council for the Protection of Memory of Combat and Martyrdom.

Lemonnier, P. (1992). Elements for an Anthropology of Technology. Anthropological Papers, Museum of Anthropology 88. Ann Arbor, MI: University of Michigan.

Levi, P. (1986). I sommersi e i salvati. Turín: Einaudi.

Littell, J. (2014). Chechnya Album. En Forensic Architecture (Eds.) Forensis. The Architecture of Public Truth (pp. 242-263). Berlin: Sternberg Press.

López Mazz, J. M. (2017). Cuando la historia se escribe con una pala. En J. M. López Mazz, E. Anstett y D. Merklen (Eds.). Después de la violencia. El presente político de las dictaduras pasadas (pp. 121-131). Montevideo: Banda Oriental.

Mbembé, J. A. (2003). Necropolitics. Public Culture, 15(1), 11-40.

Moshenska, G. (2009). Beyond the Viewing Platform: Excavations and Audiences. Archaeological Review from Cambridge, 24(1), 39-53.

Muñoz Encinar, L. (2016). De la exhumación de los cuerpos al conocimiento histórico. Análisis de la represión irregular franquista a partir de la exhumación de fosas comunes en Extremadura (1936-1948). Tesis doctoral inédita. Universidad de Extremadura, Cáceres. 
Pawlicka-Nowak, Ł. (Ed.) (2004). Chełmno Witnesses Speak. Konin and łódź, The Council for the Protection of Memory of Combat and Martyrdom in Warsaw. Konin: The District Museum of Konin.

Rathje, W. L., y Murphy, C. (1992). Rubbish!: the Archaeology of Garbage. Nueva York: Harper Collins.

Razac, O. (2015). Historia política del alambre de espino. Santa Cruz de Tenerife: Melusina.

Ren, X. (2014). The Political Economy of Urban Ruins: Redeveloping Shanghai. International Journal of Urban and Regional Research 38(3), 1081-1091.

Rodrigo, J. (2008). Hasta la raíz. Violencia durante la Guerra Civil y la dictadura franquista. Madrid: Alianza.

Salerno, M. A., Zarankin, A., \& Perosino, M. C. (2012). Arqueologías de la clandestinidad: una revisión de los trabajos efectuados en los centros de detención clandestinos de la última dictadura militar en Argentina. Revista Universitaria de Historia Militar, 2, 49-84.

Santos Herceg, J. (2016). Los centros de detención y/o tortura en Chile: Su desaparición como destino. Izquierdas, 26, 256-275.

Schindel, E. (2019). Desiertos, mares, islas: geografías de intemperie como espacios de desaparición en contextos migratorios. Ponencia presentada al seminario 'Nuevas desapariciones, nuevos espacios'. Universidad del País Vasco, Bilbao.

Schlögel, K. (2014). Terror y utopía. Moscú en 1937. Madrid: Acantilado.

Schute, I. (2018). Collecting Artifacts on Holocaust Sites: A Critical review of Archaeological Research in Ybenheer, Westerbork, and Sobibor. International Journal of Historical Archaeology, 22(3), 593-613.

Shanks, M., Platt, D., y Rathje, W. L. (2004). The Perfume of Garbage: Modernity and the Archaeological. Modernism/Modernity, 11(1), 61-83.

Skinner, M., York, H. P., y Connor, M. A. (2002). Postburial Disturbance of Graves in Bosnia-Herzegovina. En W. D. Haglund y M. H. Sorg (Eds.). Advances in Forensic Taphonomy: Method, Theory, and Archaeological Perspectives (pp. 293-308). Boca Raton, FL: CRC.

Sofsky, W. (2013). The Order of Terror: The Concentration Camp. Princeton, NJ: Princeton University Press.

Starzmann MT. (2014). Excavating Tempelhof Airfield: Objects of Memory and the Politics of Absence. Rethinking History, 18(2), 211-29.

Sturdy Colls, C. (2015). Holocaust Archaeologies: Approaches and Future Directions. Nueva York: Springer.

Theune, C. (2010). Historical Archaeology in National Socialist Concentration Camps in Central Europe. Historische Archäologie, 3, 1-14.

Theune, C. (2018). A Shadow of War. Archaeological Approaches to Uncovering the Darker Sides of Conflict from the 20th Century. Leiden: Sidestone Press.

Virilio, P. (1988). Estética de la desaparición. Barcelona: Anagrama. 
Virilio, P. (2005). Desert Screen. War at the Speed of Light. Londres: Verso.

Weizman, E. (2017). Violence at the Threshold of Detectability. En Z. Dziuban (Ed.). Mapping the Forensic Turn (pp.63-88). Viena: New Academic Press. 